\title{
Studies of Modification of Zeolite by Tandem Acid-Base Treatments and its Adsorptions Performance Towards Thorium
}

\author{
G. Nurliati $^{1,2^{\star}}$, Y.K. Krisnandi ${ }^{2}$, R. Sihombing ${ }^{2}$ and Z. Salimin ${ }^{1}$ \\ ${ }^{I}$ Center for Radioactive Waste Technology, National Nuclear Energy Agency, \\ Puspiptek Area Serpong, Tangerang 15310, Indonesia \\ ${ }^{2}$ Department of Chemistry, University of Indonesia, Depok 16424, Indonesia
}

\section{ARTICLE INFO}

\section{Article history:}

Received 26 January 2015

Received in revised form 20 May 2015

Accepted 21 May 2015

\section{Keywords:}

Natural zeolite

Tandem acid-base treatments

Hierarchical materials

Thorium adsorption

\begin{abstract}
A B S T R A C T
Hierarchical zeolite was prepared from natural zeolite using tandem acid-base treatments and applied as adsorbent for Th(IV) removal. Natural zeolite occurred naturally as microporous material. It was modified using two familiar methods simultaneously, dealumination and desilication techniques, to change its micropore size into hierarchical pores. Extensive characterization of both natural and modified zeolites were conducted using XRD, BET, SEM-EDS, and AAS. XRD Patterns of raw, pre-treated, and acid-base tandem modified zeolites show that the modification process has not changed the crystal properties of this material. However, the $\mathrm{Si} / \mathrm{Al}$ ratio is increased from 6.688 to 11.401 for Na-zeolite $(\mathrm{NaZ})$ and modified zeolite, $\mathrm{ZA} 2 \mathrm{~B}$ respectively. The surface area is increased from $125.4 \mathrm{~m}^{2} / \mathrm{g}$ (NaZ) to $216.8 \mathrm{~m}^{2} / \mathrm{g}$ (ZA2B), indicative of the creation of mesopore in addition to naturally micropore structure. The application of these zeolite materials as adsorbent were carried out using solution of $50 \mathrm{ppm} \mathrm{Th}^{4+}$ measured using UV-Vis spectrophotometer. The UV-Vis result shows that the modified zeolite (ca. $10 \mathrm{mg}$ ) has higher adsorption capacity than natural zeolite. The adsorption process does not fit into Langmuir and Freundlich isotherm and the adsorption capacity of this material increase from $909 \mathrm{mg} / \mathrm{g}$ to $2000 \mathrm{mg} / \mathrm{g}$ for NaZ and ZA2B respectively.
\end{abstract}

\section{INTRODUCTION}

Indonesia is rich with a large amount of minerals including natural zeolites. Zeolite is an aluminosilicate material with three-dimensional frameworks that consist of $\mathrm{SiO}_{4}$ and $\mathrm{AlO}_{4}$ tetrahedra arranged regularly in which each oxygen atom is shared between two tetrahedra [1]. The replacement of $\mathrm{Si}^{4+}$ with $\mathrm{Al}^{3+}$ in tetrahedral structure creates negative formal charge and counterbalanced by exchangeable cations (e.g., $\mathrm{Na}^{+}, \mathrm{K}^{+}, \mathrm{Ca}^{2+}, \mathrm{Mg}^{2+}$ ) [2].

The structure of Zeolite is filled with cavities and channels with dimensions ranging from $0.2 \mathrm{~nm}$ to $1 \mathrm{~nm}$ (micropores) inside which water molecules and countercations may reside [3]. Small ions and

\footnotetext{
* Corresponding author.

E-mail address: gustri@batan.go.id

DOI: http://dx.doi.org/10.17146/aij.2015.382
}

moleculs can pass through these channels but large ions and moleculs are excluded. Due to its microporosity and relatively high surface area, natural zeolites have been widely used as adsorbents, ion exchanger, catalysts, and separation media [1].

Despite its wide applications, natural zeolite has limitations due to (1) undesired impurity in its structure, and (2) its properties which are not optimized by nature [3]. These limitations can be overcome by modifications of the structure of natural zeolite. Dealumination and desilication are commonly employed to change the properties of natural zeolite such as $\mathrm{Si} / \mathrm{Al}$ ratio, acidity, and pore size $[3,9,13]$.

Dealumination is a process in which the framework aluminum atoms are removed without destroying the micropore structure. It can be achieved by hydrolysis of the Al-O-Si bonds using 
two common methods, i.e., thermal treatment (commonly by steaming) [4] or acid leaching [5]. Dealumination changes the $\mathrm{Si} / \mathrm{Al}$ ratio in zeolite, hence affecting the surface and acidic properties of zeolite [6]. The desilication process, where it is the silicon atoms which are removed, follows the same pattern as dealumination such as type of lattice defects and mesopore formation. The difference lies in the use of alkaline solution for leaching method [7-9]. Desilication can introduce mesoporosity to zeolite through alkaline treatment [10-12]. J.C. Groen in Huang (2014) suggested that for mordenite with optimal Si/Al ratios (20-30), mesoporosity was introduced after it was subjected to alkaline treatment $\left(0.2 \mathrm{M} \mathrm{NaOH}\right.$ at $65^{\circ} \mathrm{C}$ for $30 \mathrm{~min}$ ).

Recently, combinations of dealumination and desilication techniques have been employed in order to modify zeolite through mesopore formation [13-15]. Van Laak (2010) found that sequential acid-alkaline treatments of mordenite zeolites $(\mathrm{Si} / \mathrm{Al}=8-15)$ are effective for themesopore formation. Our research group [15] has conducted modification of zeolite by combining acid-base treatments to the natural zeolite from LampungIndonesia in order to introduce mesoporosity, and studied its capacity to adsorb $\mathrm{Cu}$ (II) from aqueous solution. The results show that acid-base treatments enhanced the surface area of the natural zeolite from Lampung-Indonesia by $350 \%$ and the adsorption capacity increase by $24 \%$.

Based on the previous work, the aims of this research are to modify natural zeolite from Bayat-Klaten, Central Java, Indonesia, by tandem acid-base treatments, and to study the effect of modification on thorium adsorption. Thorium is a naturally occurring radioactive element widely distributed over the earth's crust with a half life of $1.39 \times 10^{10}$ years. Thorium has been extensively used in various application such as light bulb elements, lantern mantles, welding electrodes, and heat-resistant ceramics. Due to its stability at ambient temperature, the direct toxicity of thorium is low. However when living organisms are exposed to thorium nitrate, thorium precipitates in a hydroxide form and is mainly localized in liver, spleen and marrow [1]. Different types of materials have been used as adsorbents for thorium, such as activated carbons and zeolites [1], perlite [16], modified clays MTTZ derivative [17], poly(methacrylic acid)grafted chitosan/bentonite composite [18], Na-bentonite [19], Al-pilared bentonite [20], and cation exchanger resin [21]. But no data were available for its adsorption on tandem acid-base modified zeolite.

\section{EXPERIMENTAL METHODS}

\section{Modification of natural zeolite}

The modification of natural zeolite from Bayat-Klaten consists of physical activation, pre-treatment, Na-exchange treatment, and post-modification by tandem acid-base treatments.

The activation of natural zeolite was performed by washing the zeolite with demineralized water $(1: 3 \mathrm{w} / \mathrm{v})$ under stirring for 3 hours. The solid phase was dried at $300^{\circ} \mathrm{C}$. The aim of physical activation is to remove water molecules from the voids of zeolite and open the zeolite's active sites.

The pre-treatment process was conducted following Ming and Dickinson [2]. The activated natural zeolite was treated with $1 \mathrm{M} \mathrm{NaOAc}$ buffer to reach a $\mathrm{pH}$ of 5; mixing with $30 \% \mathrm{H}_{2} \mathrm{O}_{2}$ and dithionite-citrate-bicarbonate to remove free carbonates, organic matters, and free iron oxides, respectively. After pre-treatment, the counterbalanced cations in zeolite were converted into sodium ions using $0.5 \mathrm{M} \mathrm{NaCl}$ solution (10 g zeolite $/ 100 \mathrm{ml}$ solution) at $80^{\circ} \mathrm{C}$ under stirring for $2 \times 8$ hours.

Post-modification was started with dealumination process, by stirring Na-zeolite in $0.6 \mathrm{M} \mathrm{HCl}$ solution (10 g zeolite/100 ml solution) at $100^{\circ} \mathrm{C}$ for 2 hours (under reflux condition). The solid phase was washed with demineralized water and dried at $65^{\circ} \mathrm{C}$. Desilication was conducted by stirring zeolite in $0.2 \mathrm{M} \mathrm{NaOH}$ solution $(3.3 \mathrm{~g}$ zeolite $/ 100 \mathrm{ml}$ solution) at $65^{\circ} \mathrm{C}$ for 30 minutes. The zeolite samples were then labeled as follow: Raw Zeolite (RZ), Pretreatment Zeolite (PZ), NaZeolite (NaZ), 1 Acid treated zeolite (ZA1), 2 acid treated zeolite (ZA2), Acid-base treated zeolite (ZA2B), and base treated zeolite (ZB1). Characterization for raw and modified zeolites were conducted with X-ray powder diffraction (XRD), Fourier transform infrared spectroscopy (FTIR), atomic absorption spectroscopy (AAS), and surface area analysis including BrunauerEmmett-Teller (BET) and Barrett-Joyner-Halenda (BJH) methods.

\section{Sorption studies}

Kinetic studies of adsorption were performed with $50 \mathrm{ppm} \mathrm{Th}(\mathrm{IV})$ solution. About $0.1 \mathrm{~g}$ zeolite was mixed with $10 \mathrm{ml}$ solution and placed in a shaker for a certain time interval. The adsorbent was then removed by centrifugation and filtration, while the thorium concentration was determined using UV-Vis spectrometer. 
The isotherm studies were conducted with the same process as in the kinetic study by varying concentration of thorium solution in the range of 5-100 ppm and the mixture was shaked for optimum adsorption time obtained from the kinetic study.

\section{RESULTS AND DISCUSSION}

The natural zeolite and its derived sample, modified with $0.6 \mathrm{M} \mathrm{HCl}, 0.2 \mathrm{M} \mathrm{NaOH}$, before and after tandem acid-base treatment, were characterized with X-ray diffraction (XRD). The $2 \theta$ values in Fig. 1 show that the main composition of natural zeolite from BayatKlaten are mordenite $\left(2 \theta=9.79^{\circ} ; 22.37^{\circ} ; 25.63^{\circ}\right.$; $27.24^{\circ}$ and $\left.27.76^{\circ}\right)$ and heulandite $\left(2 \theta=9.85^{\circ}\right.$; $\left.22.21^{\circ} ; 22.34^{\circ} ; 25.96^{\circ} ; 28.09^{\circ}\right)$. The figure shows that there were no significant changes in the XRD patterns before and after treatments. It confirms that the structure of mordenite and heulandite are preserved despite being treated tandemly with acid and/or base. Huang (2014) showed similar results to this work. The sequential steaming-acid leachingalkaline treatments did not affect the crystallinity of as-synthesized mordenite zeolite from China. Further characterization with energy-dispersive X-ray spectroscopy (EDS) (Table 1) shows that the dominant exchangeable cation in natural zeolite structure from Bayat-Klaten is $\mathrm{Ca}^{2+}$, indicative of natural zeolite from Bayat-Klaten which is Ca-mordenite and $\mathrm{Ca}$ heulandite type.

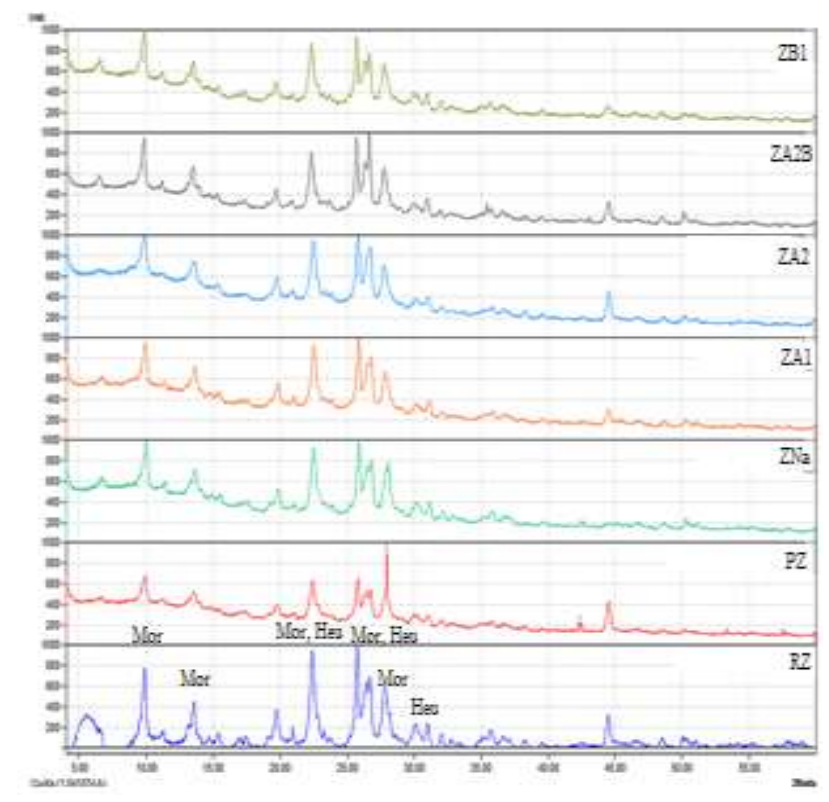

Fig. 1. XRD spectrum of raw natural zeolite and modified zeolite from Bayat-Klaten.
Table 1. Characterization of raw natural, NaZ and ZA2B-form zeolite from Bayat-Klaten using EDS

\begin{tabular}{cccc}
\hline \multicolumn{4}{c}{$\%$ Mass } \\
\hline Element & Raw Zeolite & NaZ & ZA2B \\
\hline $\mathrm{C}$ & 9.52 & 14.39 & 10.17 \\
$\mathrm{O}$ & 53.10 & 52.33 & 52.10 \\
$\mathrm{Na}$ & 0.86 & 2.16 & 3.54 \\
$\mathrm{Mg}$ & 0.52 & 0.13 & 0.13 \\
$\mathrm{Al}$ & 5.95 & 4.73 & 4.63 \\
$\mathrm{Si}$ & 25.72 & 24.40 & 28.26 \\
$\mathrm{~K}$ & 0.57 & 0.33 & 0.41 \\
$\mathrm{Ca}$ & 1.92 & 0.69 & 0.36 \\
$\mathrm{Fe}$ & 1.84 & 0.83 & 0.39 \\
\hline
\end{tabular}

\section{Post-modification treatments}

In this experiment, acid treatment causes dealumination of the zeolites, in which Al-O bonds are weakened by proton attack causing skeletal vacancies and defects. The vacancies and defects enlarge the pore openings of the zeolite, increasing the surface area and adsorption ability [22].

The dealumination process can be divided into three steps: 1) cleavage of O-Al-O bonds, 2) removal of $\mathrm{Al}$ atom leaving atomic gaps and silanol nest, and 3) refilling of empty spaces by $\mathrm{Si}$ atoms. The suggested reaction in dealumination process is showed in equation (1) $[23]$.

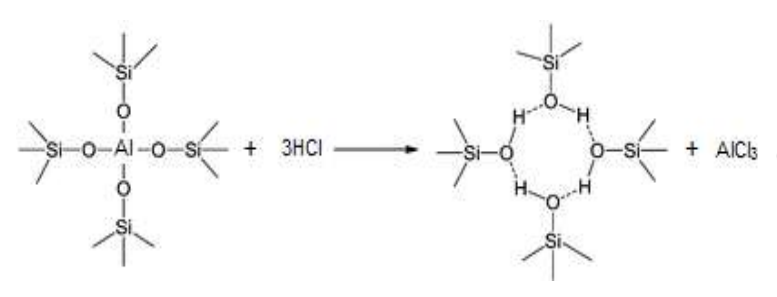

Characterization using FTIR shows stretching vibration of silanol groups at $3750 \mathrm{~cm}^{-1}$ and $\mathrm{OH}$ stretching band from silanol groups at $3540-3650 \mathrm{~cm}^{-1}$. Characteristic lattice vibrations of the zeolitic structure can be distinguished from these band: $\mathrm{H}-\mathrm{O}-\mathrm{H}$ bending band at $1630 \mathrm{~cm}^{-1}$, asymmetric stretching vibrations band at 950-1025 $\mathrm{cm}^{-1}$ and $1050-1250 \mathrm{~cm}^{-1}$, symmetric stretching vibrations bands at $750-820 \mathrm{~cm}^{-1}$ and $650-750 \mathrm{~cm}^{-1}$, double ring vibrations at $500-650 \mathrm{~cm}^{-1}$, T-O bending vibrations at 420-500 $\mathrm{cm}^{-1}$, and pore opening vibrations at $300-420 \mathrm{~cm}^{-1}[24,25]$.

Dealumination process cause wave number shifting in asymmetric stretching of the tetrahedral atoms band to the higher number. Figure 2 shows asymmetric stretching increase from $1048.72 \mathrm{~cm}^{-1}$ 
for raw zeolite to $1054.84 \mathrm{~cm}^{-1}$ and $1065.04 \mathrm{~cm}^{-1}$ for $\mathrm{NaZ}$ and dealuminated zeolite (ZA1), respectively. This shifting is caused by the leaching of Al from zeolite framework and changes on the bond strength and Si-O-Si angle [26]. Since $\mathrm{Si}$ has higher electronegativity than $\mathrm{Al}$ and $\mathrm{Si}-\mathrm{O}$ bond is shorter than the Al-O bond, the decrease of $\mathrm{Al}$ content causes the increase of $\mathrm{Si}-\mathrm{O}$ bond strength.

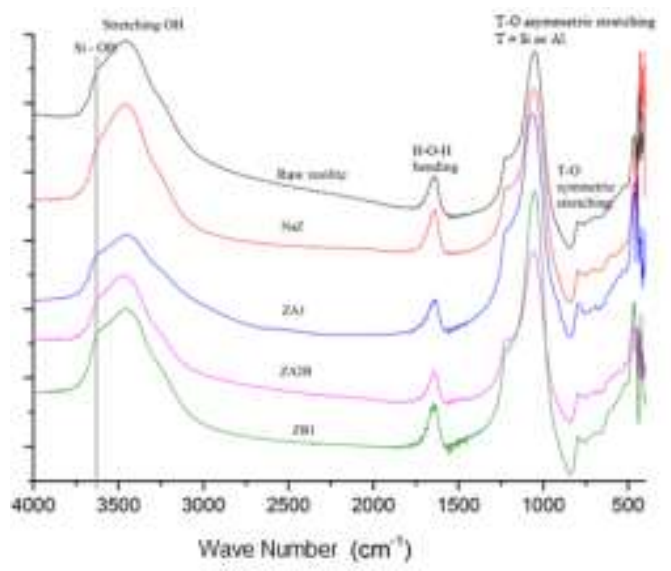

Fig. 2. FTIR spectrum of natural zeolite and its modified forms.

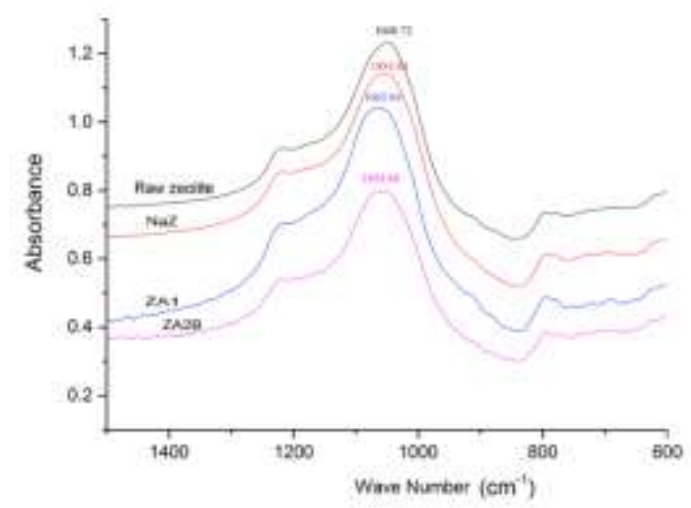

Fig. 3. Wave number shifting in natural zeolite and its modified form (enlargement of fig. 2).

The removal of $\mathrm{Al}$ atom from zeolite framework increase the $\mathrm{Si} / \mathrm{Al}$ ratio of modified zeolite. Characterization of natural zeolite and its modified form using Atomic Absorption Spectroscopy (Table 2) shows that the $\mathrm{Si} / \mathrm{Al}$ ratio after the first dealumination increase from 6.688 to 11.031 for $\mathrm{NaZ}$ and ZA1 respectively. The second dealumination also increase the $\mathrm{Si} / \mathrm{Al}$ ratio to 14.265 for ZA2. This result indicates that the dealumination process is successful, because the amount of aluminium in the structure is decreased (by 53.6\%).

The next step is alkaline treatments on both Na-exchanged and acid-treated zeolites. The aim of this treatment is to leach $\mathrm{Si}$ atoms from zeolite structure and introduce mesoporosity. Alkaline treatments increase the \% mass of $\mathrm{Si}$, but overall decreases the $\mathrm{Si} / \mathrm{Al}$ ratio of both $\mathrm{NaZ}$ (from 14.265 to 11.401 for ZA and ZA2B, respectively) and ZA2 (from 6.688 to 4.4715 for $\mathrm{NaZ}$ and $\mathrm{ZB} 1$, respectively). The $\mathrm{Si} / \mathrm{Al}$ ratio can affect the mesopore formation in zeolite. Groen et al. in Silaghi [27] found that the optimal $\mathrm{Si} / \mathrm{Al}$ ratio for introducing mesoporosity to zeolite framework is $\sim 20-50$. Below this ratio, only limited mesopore formation occured since the aluminium atoms prevent $\mathrm{Si}$ extraction from the zeolite framework.

Table 2. $\mathrm{Si} / \mathrm{Al}$ ratio of natural zeolite and its acid-base treated derivatives analysed using AAS

\begin{tabular}{lcccc}
\hline \multicolumn{1}{c}{ Zeolite } & $\begin{array}{c}\text { \% mass } \\
\text { Na }\end{array}$ & $\begin{array}{c}\text { \% mass } \\
\mathbf{S i}\end{array}$ & $\begin{array}{c}\text { \% mass } \\
\mathbf{A l}\end{array}$ & $\mathbf{S i} / \mathbf{A l}$ \\
\hline Raw zeolite & 1.515 & 79.100 & 7.085 & 11.164 \\
Z-pre treatment & 1.920 & 63.200 & 6.825 & 9.260 \\
Na-Z $^{\mathrm{a}}$ & 3.675 & 73.000 & 10.915 & 6.688 \\
$\mathrm{ZA1}^{\mathrm{b}}$ & 3.925 & 76.200 & 6.908 & 11.031 \\
$\mathrm{ZA2}^{\mathrm{c}}$ & 1.200 & 72.250 & 5.065 & 14.265 \\
$\mathrm{ZA2B}^{\mathrm{d}}$ & 1.610 & 74.050 & 6.495 & 11.401 \\
$\mathrm{ZB1}^{\mathrm{e}}$ & 4.040 & 71.450 & 15.155 & 4.715 \\
\hline
\end{tabular}

${ }^{\mathrm{a}}$ sodium homoionic form of zeolite, ${ }^{\mathrm{b}}$ first dealuminated zeolite, ${ }^{\mathrm{c}}$ second dealuminated zeolite, ${ }^{\mathrm{d}}$ tandem acid-base treated zeolite, "base treated zeolite.

Structural changes caused by desilication can be observed by FTIR (Fig. 2). The intensity of the characteristic silanol band (at $3500 \mathrm{~cm}^{-1}$ ) decreased in desilicated zeolite. This infrared characteristic is known as defect sites in zeolite. Therefore it can be deduced that alkaline attack mostly occurred in these defect sites.

The surface area, isotherm adsorption and pore distribution of zeolite were determined by Brunauer-Emmett-Teller (BET) method. Table 3 shows the enhancement of surface area of the zeolite: from $125.4 \mathrm{mg}^{2} \mathrm{~g}^{-1}$ (NaZ) to 138.0 and $216.8 \mathrm{mg}^{2} \mathrm{~g}^{-1}$ for alkaline treated zeolite, $\mathrm{ZB} 1$ and ZA2B respectively. It indicates that alkaline treatments could introduce mesoporosity in natural zeolite.

Table 3. BET characterization of raw zeolite and its modified forms

\begin{tabular}{|c|c|c|c|c|c|}
\hline Zeolit & $\underset{\left(\mathbf{m}^{2} \mathbf{g}^{-1}\right)}{\mathbf{S}_{\mathrm{ex}^{\mathrm{a}}}{ }^{\mathrm{a}}}$ & $\begin{array}{l}\text { Vmicroo }^{b} \\
\left(\mathrm{cc} \mathrm{g}^{-1}\right)\end{array}$ & $\begin{array}{l}\text { Vtotal }^{\mathrm{c}} \\
\left(\mathrm{cc} \mathrm{g}^{-1}\right)\end{array}$ & 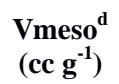 & $\begin{array}{l}\text { Rmicr } \\
\mathbf{o}^{\mathbf{e}}(\mathbf{n m})\end{array}$ \\
\hline $\begin{array}{c}\text { Raw } \\
\text { zeolite }\end{array}$ & 140.0 & 0.05934 & 0.1357 & 0.07636 & 0.62 \\
\hline $\mathrm{NaZ}$ & 125.4 & 0.04642 & 0.1109 & 0.06448 & 1.02 \\
\hline $\mathrm{ZA} 1$ & 120.6 & 0.04864 & 0.1395 & 0.09086 & 0.66 \\
\hline ZB1 & 138.0 & 0.05773 & 0.1326 & 0.07487 & $\mathrm{td}$ \\
\hline ZA2B & 216.8 & 0.09795 & 0.1804 & 0.08245 & 0.52 \\
\hline
\end{tabular}

${ }^{\mathrm{a}}$ Multipoint BET, ${ }^{\mathrm{b}}$ t-method, ${ }^{\mathrm{c}}$ at $\mathrm{P} / \mathrm{Po}=0.992594$

${ }^{\mathrm{d}}$ Vtotal-Vmicro, ${ }^{\mathrm{e}} \mathrm{DA}$ method pore radius (mode) 
The $\mathrm{N}_{2}$ isotherm adsorption of zeolite and its modified zeolite forms in Fig. 4 shows that there is hysteresis loop in the isotherm adsoption curve of desilicated zeolite ZA2B and ZB1 (Fig. 4 (d) and (e)). The curve is following IUPAC isothermal curve type four, which indicated there are capillary condensation in mesopourous material [28].

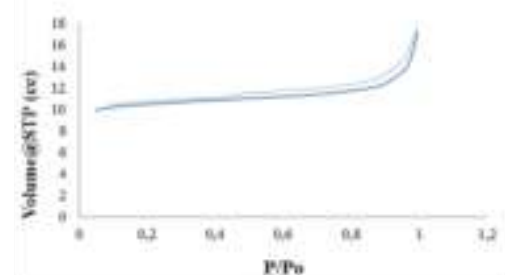

(a)

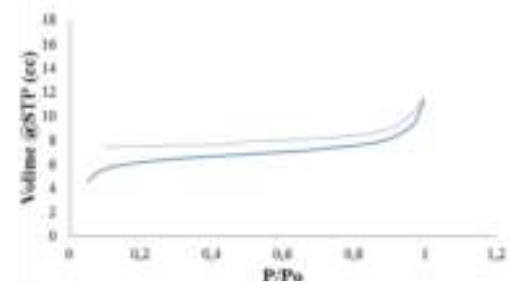

(b)

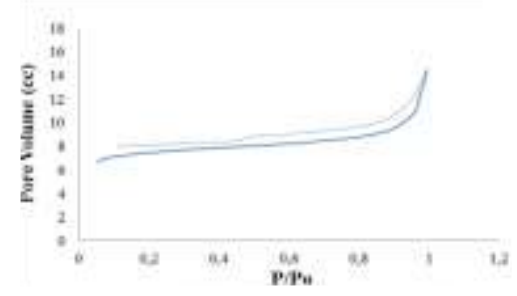

(c)

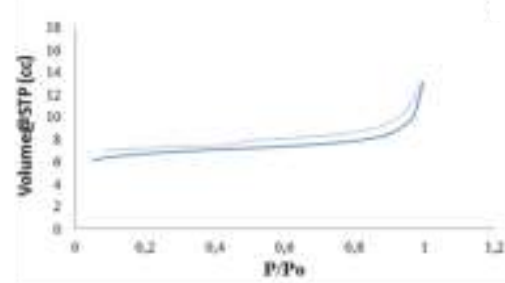

(d)

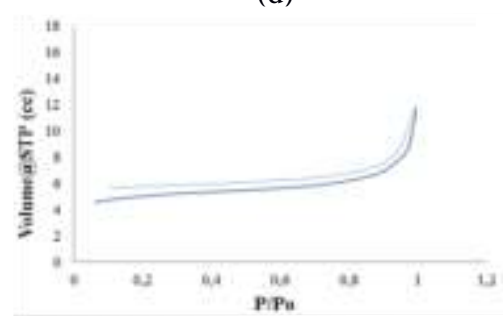

(e)

Fig. 4. Nitrogen isotherm adsorption curve of natural zeolite and its modified forms, (a) Raw zeolite, (b). NaZ, (c). ZA1, (d). ZB1, (e). ZA2B (bold line):adsorption (dash line): desorption.

Barrett-Joyner-Halenda (BJH) analysis shows the pore size distribution in zeolite. Figure 5 (a) shows that pore size (diameter, $\varnothing$ ) distribution in raw zeolite is $<2 \mathrm{~nm}$ as well as in $\mathrm{NaZ}$
(Fig. 5 (b)), ZA1 (Fig. 5 (c)) and ZB1 (Fig. 5 (d). While in ZA2B (Fig. 5 (e) and enlarge in Fig. 6), pore size distribution lies in $\mathrm{d}<2 \mathrm{~nm}$ and $2-8 \mathrm{~nm}$. The existence of $2-8 \mathrm{~nm}$ pores indicated that tandem acid-base treatments can introduce mesoporosity in zeolite, leading to the hierarchical structure of zeolites.

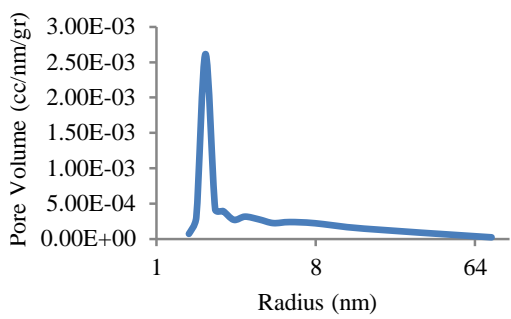

(a)

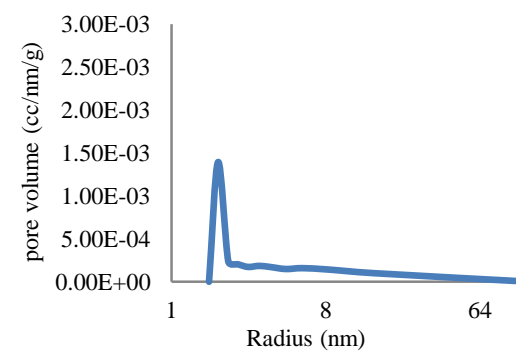

(b)

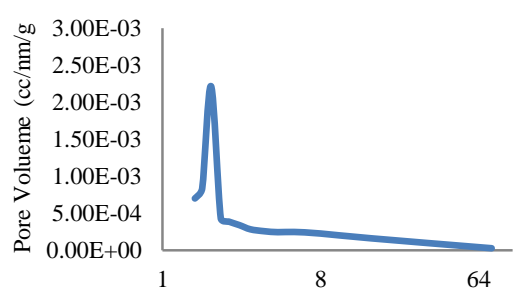

Radius (nm)

(c)

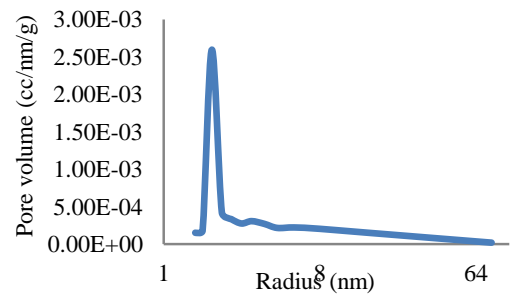

(d)

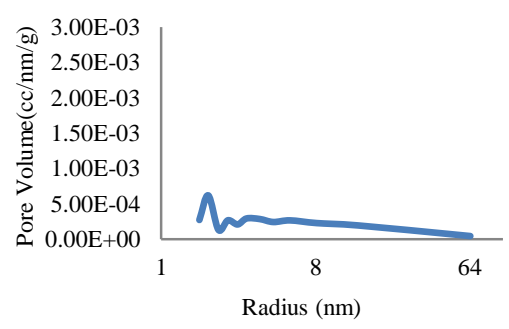

(e)

Fig. 5. BJH desorption curve of natural zeolite and its modified forms (a) Raw zeolite, (b) NaZ, (c) ZA1, (d) ZB1, (e) ZA2B . 


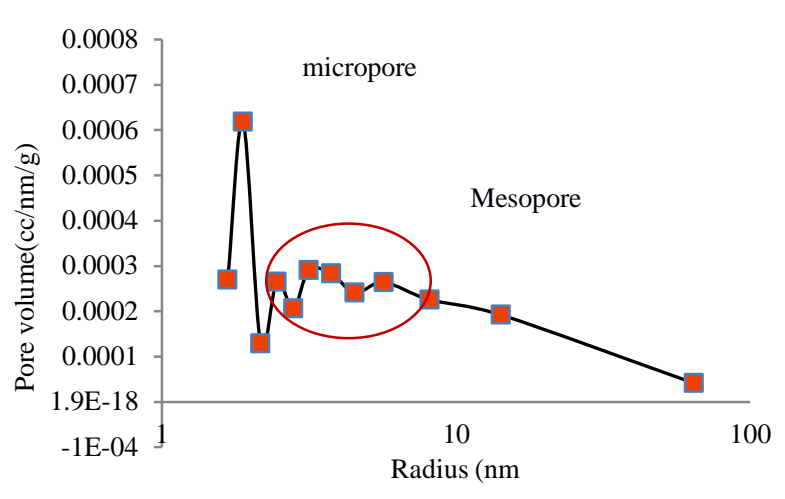

Fig. 6. BJH desorption curve of ZA2B (enlargement of Fig. 5).

Figure 7 (a) suggests that the schematic mechanism of optimal mesopore formation in zeolite upon alkaline treatment. Since the $\mathrm{Si} / \mathrm{Al}$ ratio of parent zeolite (ZA2) used for desilication process is below 20, the $\mathrm{Al}$ atoms prevent $\mathrm{Si}$ extraction hence the formation of mesopore $(\varnothing>2 \mathrm{~nm})$ in this work is limited, as illustrated in Fig. 7 (b).

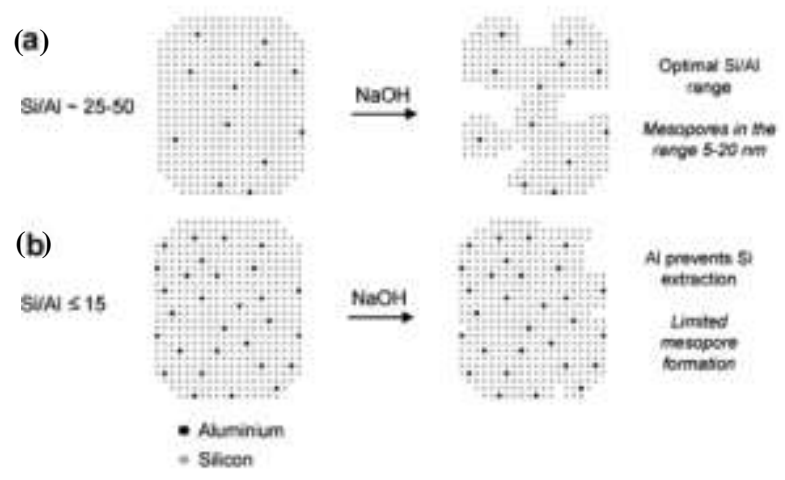

Fig. 7. The schematic mechanism of mesopore formation in zeolite upon alkaline treatment (extracted from [21]).

\section{Soption studies}

This sorption studies focused on the removal of thorium. The aim of this experiment was to determine the optimum adsorption time and the adsoption capacity of zeolites before and after modification. UV-vis spectrometer analysis (Fig. 8) shows that the optimum time for adsorption of $50 \mathrm{ppm}$ Th(IV) solution is 120 minutes for both NaZ and ZA2B. Furthermore, it can be seen that after 180 minutes the adsorption capacity tends to decrease, especially for the modified zeolite, namely ZA2B. This indicates that some $\mathrm{Th}^{4+}$ was leaching from the zeolite, possibly because the concentration equilibrium between $\mathrm{Th}^{4+}$ inside and outside zeolite may be shifted.

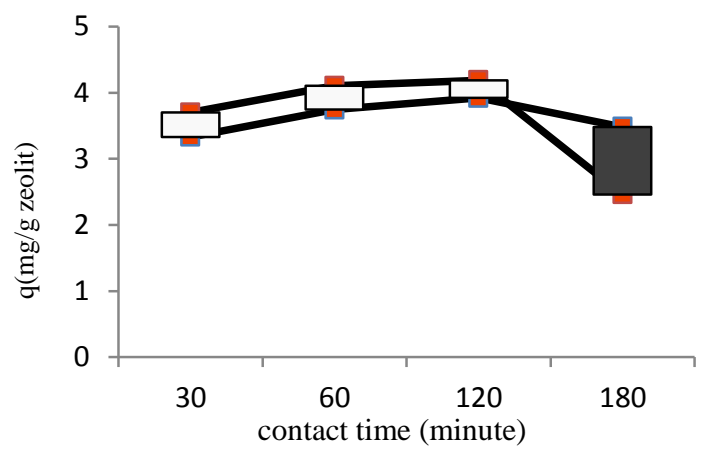

Fig. 8. UV-vis spectrometer analysist for determination of optimum contact time in adsorption of $\mathrm{Th}(\mathrm{IV})$ by $\mathrm{NaZ}$ (bold line) and ZA2B (dash line).

The determination of the adsorption capacity of zeolite was conducted by varying the concentration of thorium and contacting the thorium-containing solution with zeolite for 120 minutes. Figure 9 shows that adsorption capacity of acid-base treated zeolite (ZA2B) is slightly higher than natrium homoionic form (NaZ). Because the initial concentration of thorium solution used was relatively low (only up to $100 \mathrm{mg} / \mathrm{L}$ ) then the difference was not significant and the adsorption had not reached saturation (as can be seen in Fig. 9 the adsorption curves are still increasing and had not reached a plateau). Nevertheles, the acid-basetreated zeolite removed higher quantities of thorium because of its larger framework channels and their higher number of ion-exchange sites.

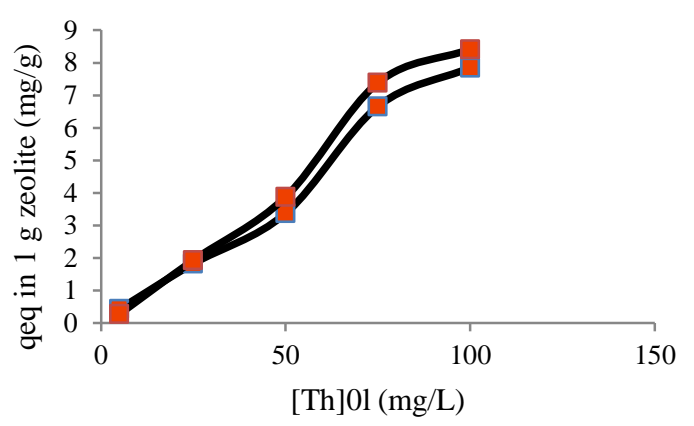

Fig. 9. UV-Vis characteristic of Th(IV) adsorption by $\mathrm{NaZ}$ (bold line) and ZA2B (dash line).

To determine the adsorption capacity quantitatively, the isotherm data are fitted to different isotherm adsorption models. Adsorption isotherm describes the equilibrium of liquid adsorption on solid surface. Two commonly used adsorption isotherm models on solid surface are the Langmuir and Freundlich models. The Langmuir equation shown in eq (2) [29]:

$$
\frac{C_{\text {tu }}}{q}=\frac{1}{q_{m} b}+\frac{C_{\text {eu }}}{q_{m}}
$$


$\mathrm{C}_{\mathrm{eq}}$ is ion concentration in equilibrium solution $(\mathrm{mg} / \mathrm{L}$ or $\mathrm{mmol} / \mathrm{L}), \mathrm{q}$ is adsorption per gram of adsorbent which is obtained be dividing the amount of adsorbate by the weight of the adsorbent ( $\mathrm{mg} / \mathrm{g}$ or $\mathrm{mmol} / \mathrm{g}$ ) and $\mathrm{q}_{\mathrm{m}}$ is adsorption capacity $(\mathrm{mg} / \mathrm{g}$ or $\mathrm{mmol} / \mathrm{L})$. Hence, if a graph of $\mathrm{C}_{\mathrm{eq}} / \mathrm{q}$ is plotted against $\mathrm{C}_{\mathrm{eq}}$, it will be a straight line, and adsorption capacity is $1 /$ slope.

The Freundlich equation is shown in eq (3):

$$
\log q_{e}=\log K_{F}+1 / n \log C_{e}
$$

$\mathrm{n}$ is a constant value related to adsorption energy. $\mathrm{K}$ is a constant value related to adsorbent capacity.

Figure 10 shows that R-square value of both Langmuir and Freundlich isotherm model are far from the expected value (ca. 1). It means that the adsorption of thorium in zeolite does not fit in both isotherm models.

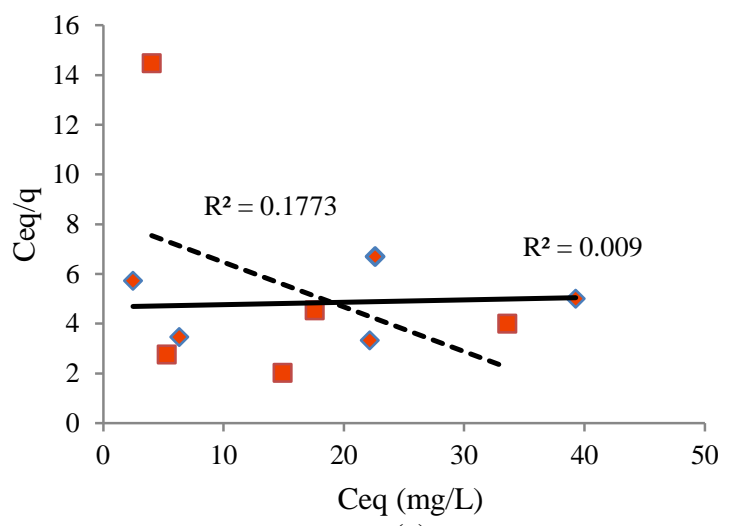

(a)

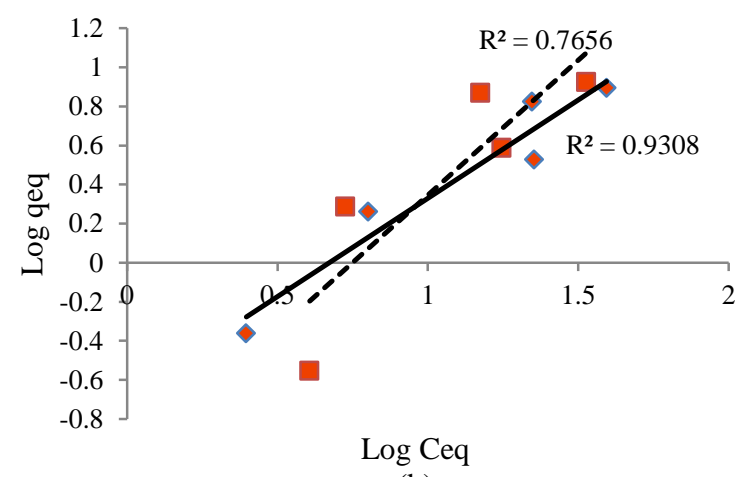

(b)

Fig. 10. Linearization of Langmuir isotherm (a) and Freundlich isotherm (b) NaZ (bold line) and ZA2B (dash line).

To determine adsorption capacity, equation 4 , that is modified from equations in Langmuir and Freundlich isotherm models, is used instead [29].

$$
\frac{C_{e q}^{1 / n}}{q}=\frac{1}{q_{m} b}+\frac{C_{e q}^{1 / n}}{q_{m}}
$$

If $\mathrm{C}_{\mathrm{eq}}{ }^{1 / n} / \mathrm{q}$ is plotted against $\mathrm{C}_{\mathrm{eq}}{ }^{1 / \mathrm{n}}$, a straight line arises, hence the adsorption capacity is proportional with $1 /$ slope.

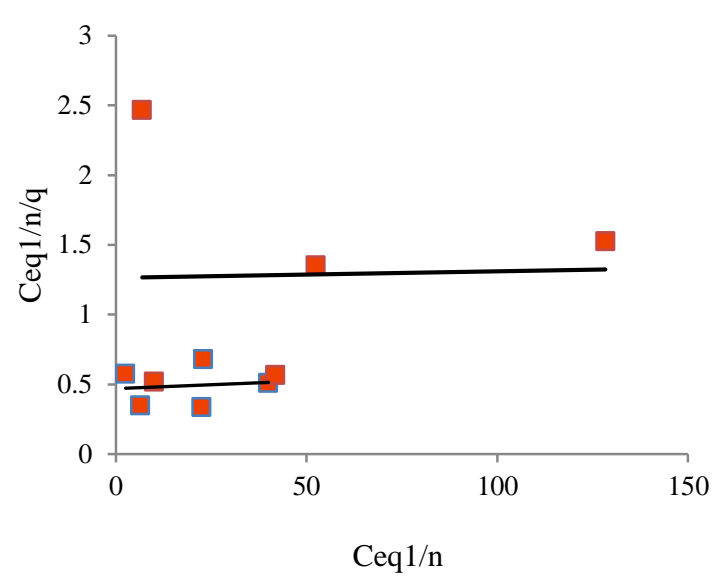

Fig. 11. Langmuir-Freundlich isotherm adsorption by $\mathrm{NaZ}$ (bold line) and ZA2B (dash line).

The adsorption capacity of both zeolites (NaZ and ZA2B) shows in Table 4 indicate that tandem acid-base treatments of natural zeolite from Bayat-Klaten (ZA2B) can improve its adsorption capacity significantly, by as high as ca. $120 \%$, compared to its homoionic form (NaZ). This result is higher than previous work of our research group [15].

Talip et al. [16] used expanded perlite to adsorp thorium from aqueous solution and found that its maximum thorium uptake capacity was $84 \pm 4 \%$ and the adsorption reached equilibrium within 60 minutes. Guerra et al. [17] modified diquite and bentonite mineral samples from the Amazon region, Brazil with MTTZ derivative (5mercapto-1-methyltetrazole) and the modification increased the thorium removal rate to $13 \%$ and $9 \%$ for diquite and bentonite respectively (The degree of reaction was estimated $80 \%$ for $\mathrm{D}_{\mathrm{MTTZ}}$ and $65 \%$ for $\mathrm{B}_{\text {MTTZ }}$ samples). Kaygun et al. [30] modified clinoptilolite (CLI) from Turkey with polyacrilonitrile (PAN) and found the equilibrium as 97.97\% sorption of thorium (IV) solution was reached within 45 minutes. Metaxas et al. [1] compared thorium removal by different adsorbents, i.e. two types of activated carbons extracted from olive pulp (carbon ACOP) and olive stone (carbon ACO), two types of natural zeolites (Na-CLI and $\mathrm{Na}-\mathrm{MOR}$ ), and two types of synthetic zeolites ( $\mathrm{NaX}$ and $\mathrm{NaA}$ ). They found that percentage thorium removal for carbon ACOP, carbon ACO, Na-CLI, $\mathrm{Na}-\mathrm{MOR}, \mathrm{NaA}$ and $\mathrm{NaX}$ were $70.30 \%, 42.5 \%$, $14.55 \%, 37.65 \%, 50.40 \%$, and $71.15 \%$, respectively.

The percentage thorium removal from this work were $71.5 \%$ for $\mathrm{NaZ}$ and $76.5 \%$ for ZA2B. Thus, it can be seen that modification of zeolite 
from Bayat-Klaten has higher adsorption capacity than Na-CLI, Na-MOR, NaX, NaA, activated carbons, and modified bentonite with MTTZ. This might be caused by the acid-base treatments increasing the zeolite's framework channels and ion-exchange sites. But it has a lower removal capability than manufactured expanded perlite, CLI(PAN), and modified diquite with MTTZ. This is probably because the manufactured expanded perlite has uniform active sites and the presence of MTTZ molecules which are intercalated in the diquite structures enhanced its surface area significantly (from $25 \mathrm{~m}^{2} \mathrm{~g}^{-1}$ to $178.8 \mathrm{~m}^{2} \mathrm{~g}^{-1}$ ) while composite material such as CLI(PAN) have better selectivity for the capture of thorium ions, and smaller solubility in water than the respective inorganic compound [30]. However, as the manufactured adsorbents undergo a certain process to get into the final form, the cost-effectiveness of using each of these groups of adsorbents should be considered in addition to the simplicity of modification procedure and the abundance of the inorganic materials in nature. Thus, tandem acid-base treatment is a simple, effective and economical procedure to modified natural zeolite as thorium adsorbent. The comparison of thorium uptake capacity on different adsorbents is given graphically in Fig. 12.

Table 4. Adsorption capacity of thorium using natural zeolite

\begin{tabular}{lcc}
\hline Zeolite* & Slope & Adsorption capacity $(\mathrm{mg} / \mathrm{g})$ \\
\hline NaZ & 0,0011 & 909 \\
ZA2B & 0,0005 & 2000 \\
\hline
\end{tabular}

NaZ: homoionic form zeolite

ZA2B: tandem acid-base treated zeolite

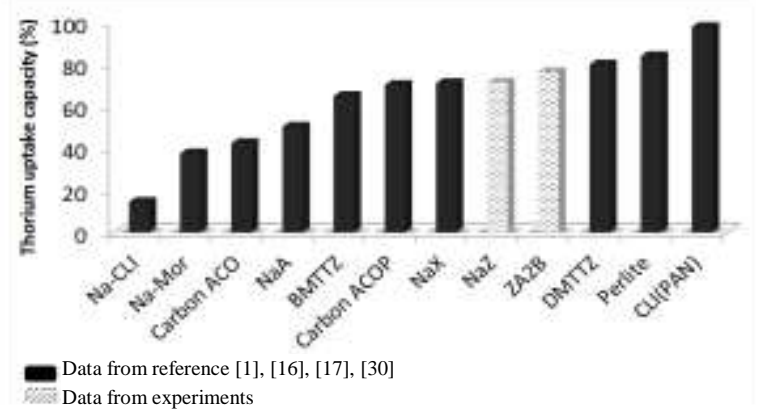

Fig. 12. The comparison of thorium uptake capacity on differen adsorbents.

\section{CONCLUSION}

The modification of natural zeolite from Bayat-Klaten using tandem acid-base treatments has successfully introduced mesoporosity in zeolite framework providing hierarchical porosity, thus improving its properties. Dealumination treatment decreased the amount of aluminium in the structure by $53.6 \%$ and changed the $\mathrm{Si} / \mathrm{Al}$ ratio of zeolite to 14.265. Desilication treatment increased the surface area of zeolite by $72.9 \%$ and introduced mesoporosity in the zeolite framework. This preliminary study shows that hierarchical porosity plays an important role in the adsorption capacity of zeolite. The tandem method is shown as a potential technique for modifying natural zeolites that could give them added value and functions.

To conclude, the sorption studies show that the thorium ion adsorption capacity of acid-base treatments zeolite (ZA2B) is $120 \%$ higher than that of the natrium homoionic form $(\mathrm{NaZ})$. Further work should be carried out to study the stability of thorium-filled hierarchical zeolite in matrix so that this work can be useful in handling aqueous radioactive wastes through immobilization process.

\section{ACKNOWLEDGMENT}

We thank Bambang Sugeng, Dr. Adel Fisli, and Sugeng Purnomo S.ST from National Nuclear Energy Agency for help in XRD, BET, and AAS analysis, respectively.

\section{REFERENCES}

1. M. Metaxas, V. Kasselouri-Rigopoulou, P. Galiatsatou et al., J. Hazard. Mater. B97 (2003) 71.

2. D.W. Ming and J.B. Dixon, Clays Clay Miner. 35 (1987) 463.

3. J. Weitkamp, Solid State Ionic $\mathbf{1 3 1}$ (2000) 175.

4. M. Muller, G. Harvey and R. Prins, Microporous Mesoporous Mater. 34 (2000) 135.

5. M. Boveri, C. Marques-Alvarez, M.A. Laborde et al., Catal. Today 114 (2006) 217.

6. M.D. González, Y. Cesteros and P. Salagre, Microporous and Mesoporous Mater. 144 (2011) 162.

7. F.C. Meunier, D. Verboekend, J.P. Gilson et al., Microporous and Mesoporous Mater. 148 (2012) 115.

8. W.C. Yoo, X. Zhang, M. Tsapatsis et al., Microporous and Mesoporous Mater. 149 (2011) 147. 
9. V. Paixão, A.P. Carvalho, J. Rocha et al., Microporous and Mesoporous Mater. 131 (2010) 350 .

10. K. Sadowska, K. Góra-Marek, M. Drozdek et al., Microporous and Mesoporous Mater. 168 (2013) 195.

11. V. Paixão, R. Monteiro, M. Andrade et al., Applied Catalysis A: General 402 (2011) 59.

12. B. Gil, Ł. Mokrzyckib, B. Sulikowski et al., Catalysis Today 152 (2010) 24.

13. A.N.C. van Laak, S.L. Sagala, J. Zecevic et al., J. Catal. 276 (2010) 170.

14. S. Huang, X. Liu, L. Yu et al., Microporous and Mesoporous Mater. 191 (2014) 18.

15. D.Y. Christine, Preparation and Characterization of Mesopore Zeolite from Natural Zeolite using Tandem Acid-Base Treatments, Undergraduate Thesis, University of Indonesia (2014). (in Indonesian)

16. Z. Talip, M. Eral and Ü. Hiçsönmez, Journal of Environmental Radioactivity 100 (2009) 139.

17. D.L. Guerra, R.R. Viana and C. Airoldi, Hazardous Materials 168 (2009) 1504.

18. T.S. Anirudhan, S. Rijith and A.R. Tharun, Colloids and Surfaces A: Physicochem. Eng. Aspects 368 (2010) 13.

19. Duo-qiang Pan, Q. Fan and P. Li, Chemical Engineering Journal 172 (2011) 898

20. E.S. Wulandari, Utilization of Aluminium Pilared Bentonite in the Treatment of Thorium Waste from Mantle Lantern Fabrication, Undergraduate Thesis, Nuclear Technology Academy (2011). (in Indonesian)
21. A.G.S. Nainggolan, Adsorbtion of Thorium from Contaminated Lantern Mantle Waste Soils with Cation Exchange Resin and its Immobilization with Polimer, Undergraduate Thesis, Diponegoro University (2011). (in Indonesian)

22. X. Wang, O. Ozdemir and M.A. Hampton, Water Research 46 (2012) 5247.

23. R. Meilani, Activity and Stability of Dealuminated Natural Zeolite from Lampung (with $\mathrm{HCl}$ and $\mathrm{HF}$ ) on Etanol Dehidration Reaction, Undergraduate Thesis, University of Indonesia (1999). (in Indonesian)

24. J. Jiao, Quantitative Characterization of Aluminum in Non-hydrated Zeolite Catalysts by Multi-nuclear Solid-state NMR Spectroscopy, Ph.D Thesis, Stuttgart University (2006).

25. G.E. Christidis, D. Moraetis and E. Keheyan, Applied Clay Science 24 (2003)79.

26. F. Cakicioglu-Ozkan, Microporous and Mesoporous Materials 77 (2005) 47.

27. M.C. Silaghi, C. Chizallet and P. Raybaud, Microporous and Mesoporous Mater. 191 (2014) 82.

28. S. Octaviani, Synthesis and Characterization of ZSM-5 Mesopore Zeolite with Desilication Method and Preliminary Study of Oxidation Catalysist of Methane, Undergraduate Thesis, University of Indonesia (2012). (in Indonesian)

29. U.T. Santoso, D. Umaningrum, U. Irawati et al., Indo. J. Chem. 8 (2008) 177. (in Indonesian)

30. A.K. Kaygun and S. Akyil, Journal of Hazardous Material 147 (2007) 357. 